\title{
Harmonizing Core Platforms In The Delivery of Patient-Specific Cell Therapies To Accelerate Patient Access To Life-Changing Treatments
}

\author{
Alex Klarer* \\ Senior Biomedical Engineer, Hitachi Chemical Advanced Therapeutics Solutions, USA \\ *Corresponding author: Alex Klarer, Senior Biomedical Engineer, Hitachi Chemical Advanced Therapeutics Solutions, USA. \\ To Cite This Article: Alex Klarer. Harmonizing Core Platforms In The Delivery of Patient-Specific Cell Therapies To Accelerate Patient Access To \\ Life-Changing Treatments. Am J Biomed Sci \& Res. 2019 - 6(1). AJBSR.MS.ID.000995. DOI: 10.34297/AJBSR.2019.06.000995.
}

Received: 眥 October 11, 2019; Published: 眥 November 05, 2019

\section{Introduction}

As our knowledge of human biology has grown, the newly found information has been leveraged to devise increasingly complicated treatments. This began with small molecule treatments that impact cell functions and has led to the rapidly maturing biologics space that largely aims to upregulate and downregulate those functions. This, in turn, has led to the emerging field of cell and gene therapy, where the aim is to create, renew, or replace cell functions and directly affect human tissue. Significant excitement has led this field to evaluate its' benefits in a breadth of disease areas with leading candidates in oncology and congenital blood diseases. However, along with this anticipation comes questions about how the pharmaceutical industry will support these complicated and, therefore, expensive treatments to ensure patients are able to benefit from these potentially life-changing therapies.

While the indications that are best treated by these medicines are still to be determined, clinical trials have shown enough early success to make the industry confident in the long-term clinical impacts of this therapeutic avenue. With that in mind, current therapies are sheltered from the institutional inefficiencies of their delivery pathways by servicing small patient populations in medically competent locales. To understand the influences on patient access, developers must look at the delivery pathway for cell and gene therapies from a needle to needle viewpoint, especially for autologous therapies, as seen in (Figure 1).

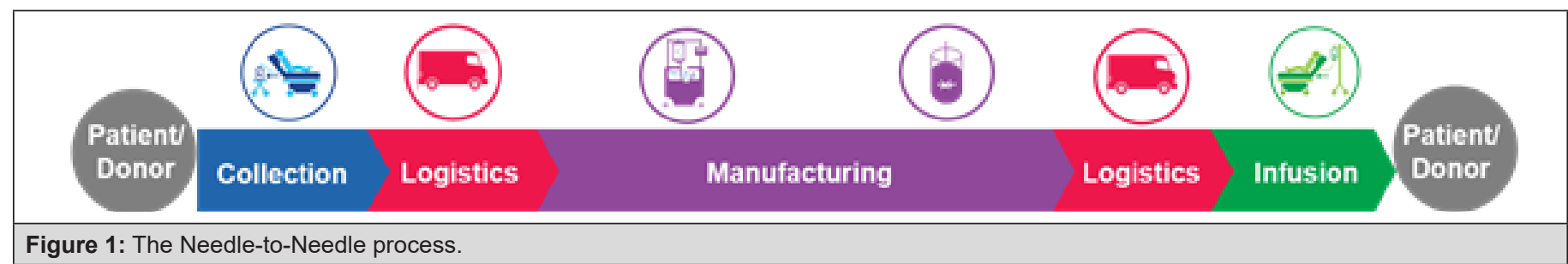

The needle-to-needle process is typically delivered by three main parties: the clinical site that handles tissue collection and drug product infusion, the manufacturing site that turns the human tissue into drug product and the logistics carrier that transports human tissue or drug product between the clinical site and the manufacturing site in a controlled manner. Each of these platforms have begun to overcome internal inefficiencies through the sharing of information, advancing application technology and growing the available pool of investment. The industry now has several centers of excellence around the world supplying therapies that have been manufactured with novel techniques and equipment, with the logistical needs understood and operationally effective.
However, internal efficiency has not led to seamless delivery. Today, scheduling patients for collection and infusion is coordinated manually between sites and a lack of transparency between participants in the delivery process threatens the scalability for autologous and many allogeneic cell and gene therapies [1].

In response to the guidance from regulatory industries, one of the first commercial CAR-T cell manufacturers, Kite, a Gilead Company, directed the paradigm toward systems similar to their chosen platform in Vineti2. To date, most conversation has been around automating the chain-of-custody and chain-of-identity to, as a result, streamline product logistics. These systems facilitate the 
chain-of-custody by consolidating track-and-trace activities in one system; this allows each party visibility on the last action input into the system. The function creates assurances that the correct item has been transferred and allows clinical sites and manufacturers to more effectively schedule. However, this is as connected as the needle-to-needle process has become; there is still a need to provide visibility beyond product location to ensure products are ready when patients need them.

Consider just a piece of the delivery pathway. When the product is nearly ready for quality release, the logistics partner and clinical site coordinate to ensure the patient can be infused with the product as soon as possible. This involves independent, manual coordination between each group about the product release timeline, including design of the transit path given the anticipated weather conditions and scheduling the patient who may have significant travel time of their own to make it to a clinic. If anything were to delay the product's release, all of this effort may have to be expended again. The process requires transparency within each of the core delivery platforms to facilitate planning and preparation in the other two. Without it, the cost of these therapies will be inflated by idle staff and wasted resources on rework.

This is not to claim that this problem has not been previously identified and that companies are not acting against it. However, a solution created unilaterally will be influenced by the unique incentives of the originating party. We see this elsewhere in the medical industry: health technology companies and clinical practices are forced to align to each partner hospital's electronic medical record software and are subject to increasing overhead costs as a result. If the cell and gene therapy industry were to find itself in a similar position, each core platform of the delivery pathway would be required to support a diverse array of operational and electronic systems employed by their partners.

They are then burdened to train personnel on each system, maintain an IT department to remediate issues as each electronic system evolves, and absorb the inefficiencies of systems that were not designed to work in tandem. The industry requires a cross-platform understanding of incentives and obstacles to most effectively address this gap. Developing the answer in this manner will allow the delivery pathway to operate as a cohesive system as opposite to distinct pillars.

In order to achieve this, we need to develop partnerships and working groups that span all stakeholders to design a system that can provide transparency, while respecting appropriate business confidentiality. A partnership or joint venture that incorporates the knowledge and informal learnings from the appropriate groups would be a way to balance incentives and generate the most valuable solution. Such a solution would take into consideration the current state of the delivery pathway, electronic systems to manage the chain-of-custody and identity with underlying manual documentation and communication, while building capability to support the future state: fully integrated, electronic systems at every point in the delivery pathway. When manufacturing capacity is better optimally utilized, this will ensure that patients receive the treatments they need regardless of irregularities upstream. A new therapeutic delivery pathway requires a new mindset when deriving solutions.

\section{References}

1. Trategic Partnership will Connect Vitruvian's Cloud-Based Software with Kite Pharma's Kite Konnect ${ }^{\mathrm{TM}}$ Platform to Enable CommercialScale Logistics for T-cell Therapies. Business wire a Berkshire Hathaway company, USA. 